http://jmscr.igmpublication.org/home/ ISSN (e)-2347-176x ISSN (p) 2455-0450

crossref DOI: https://dx.doi.org/10.18535/jmscr/v9i2.19

\title{
Dyslipidemia Associated with Hypertension Increases the Risks for Coronary Heart Disease: A Case-Control Study in a tertiary level hospital in Bangladesh
}

\author{
Authors \\ Lieutenant Colonel Dr Md. Fakhrul Alam, Dr Israt Jahan', Dr Md. Ataul Hoque \\ ${ }^{1}$ BSP, MPH, Commanding Officer, 11 Field Ambulance, Savar Cantonment, Bangladesh \\ ${ }^{2}$ Medical Officer, Savar Upazila Health Complex, Savar, Bangladesh \\ ${ }^{3}$ Associate Professor, Pediatric Cardiology, National Institute of Cardiovascular Diseases (NICVD), \\ Dhaka \\ *Corresponding Author \\ Lieutenant Colonel Dr Md. Fakhrul Alam
}

\begin{abstract}
Objective: In this study our main goal is to evaluate the effect of dyslipidemia Associated with Hypertension for Coronary Heart Disease.

Method: This case control type of study was conducted in Cardiology Department of National Institute of Cardiovascular Diseases (NICVD), during January 2018 until December 2019. Study subjects were selected from admitted patient with acute coronary syndrome at emergency department and at in-patient department of the Cardiology Department.

Results: During the study, in case group dyslipidemia and hypertension were present in $77 \%$ and $62.5 \%$ patients. Where as in control group it was $30 \%$ and 20\%. In cas group mean \pm SD of systolic blood pressure was found $134.75 \pm 19.25$ and random blood sugar was found in $223.81 \pm 72.18 \mathrm{mg} / \mathrm{dl}$. In full model of dyslipidemia with CHD interaction between dyslipidemia and hypertension were found as confounder.

Conclusion: From our study, it is concluded that dyslipidemia and hypertension are established risk factors of prime importance in CHD development. Relationship of dyslipidemia with coronary heart disease in hypertension is significant. Additional research, in particular longitudinal studies, is needed to explore the complex interaction of these factors and to inform policies and programs for the inhibition and supervision of CHDs in Bangladesh.

Keywords: Coronary heart disease (CHD), dyslipidemia, hyperlipidemias.
\end{abstract}

\section{Introduction}

Dyslipidemia is the most common risk factor of CHD for the excessive level of lipids in blood. Most dyslipidemias are hyperlipidemias in developing countries; that is, an accumulation in blood lipids.
Sometimes because of diet and lifestyle. A longer rise in insulin concentrations can also contribute to dyslipidemia. The classification of dyslipidemia into primary and secondary forms. Primary dyslipidemia is normally inherited. Secondary dyslipidemia is acquired disease. It occurs because 
of other factors, for example obesity or diabetes. Dyslipidemia is the first major risk factor for coronary artery disease, which is generally accepted (CHD). ${ }^{1-4}$ CHD was 18 times more likely to grow according to hypertension with dyslipidemia category than with nondyslipidemics. ${ }^{9}$

The world's leading cause of morbidity and mortality remains coronary heart disease (CHD), in particular myocardial infarction secondary to coronary artery atherosclerosis. The fibroproliferative condition of medium-sized and large arthritis, primarily caused by cumulative lipid is a chronic multifocal immunocomorphic atherosclerosis. The major risk factors for CHD include elevated concentrations of Total lipoprotein cholesterol (TC and LDL-C) as well as low concentrations of triglycerides (TG) and highdensity HDL-C lipoprotein cholesterol. LDL-C is called 'bad cholesterol' because an elevated risk of coronary heart attack and stroke is linked with too much cholesterol content.

Dyslipidemia may also be a condition for CHD, before other significant threats arise. The predominant lipid disorders in Asians have been higher than those of non-Asians in research. ${ }^{6}$

In this study our main goal is to evaluated the effect of dyslipidemia associated with hypertension for Coronary Heart Disease.

\section{Objectives}

$>$ To assess the effect of dyslipidemia Associated with Hypertension for Coronary Heart Disease.

$>$ To identify risk factors for CHD in Bangladeshi patients with CHD.

\section{Methodology}

This case control type of study was conducted in Cardiology Department of National Institute of Cardiovascular Diseases (NICVD), during January 2018 until December 2019. Study subjects were selected from admitted patient with acute coronary syndrome at emergency department and at in-patientdepartment of the
Cardiology Department. Sampling technique was purposive. During the study period this casecontrol study used is use secondary data from medical record data from the NICVD. To reduce the risk of selection bias in this study is use of simple randomization. The depended variable was incidence of coronary heart disease (CHD), and the main independent variable was dyslipidemia status. The potential confounding variables age, gender, family history of CHD, smoking habit, hypertension or history of hypertension, diabetes or history of diabetes, and obesity.

\section{Inclusion Criteria}

The sample of case group was patients diagnosed with CHD by the doctor, randomly selected a total of 82 respondents, while the control group considered with patients diagnosed with Atrial Fibrillation and Flutter (AFF) by a physician, randomly selected 81 respondents.

\section{Exclusion Criteria}

Patients with no symptom of CHD and dyslipidemia excluded from this study.

\section{Data Analysis}

The data were analysed using a binomial regression statistic test where an interaction assessment and confounding test were conducted. The interaction between dyslipidemia status variable and potential confounding variables was assessed using the forward method, in which the interaction variables were entered one by one into logistic regression model. Variables were considered to interact if they had a $\mathrm{p}$ value $<0.05$. The assessment of confounders was done by removing candidate confounding variables one by one, starting from the variable with the highest Wald $\mathrm{p}$ value. If the variable after being issued from the model caused on odds ratio (OR) of dyslipidemia status variable change greater than $10 \%$, the variable was considered a confounder and remained in the model.

\section{Results}

Table-1 show risk factor analysis of the patients where in case group dyslipidemia and 
hypertension were present in $77 \%$ and $62.5 \%$ patients. Where as in control group it was $30 \%$ and $20 \%$. The following table is given below in details:

Table-1: Distribution of risk factors for CHD in patients

\begin{tabular}{|l|c|c|}
\hline \multirow{2}{*}{ Variable } & Case (n= 82) & Control (n = 81) \\
\cline { 2 - 3 } & $\mathbf{\%}$ & $\mathbf{\%}$ \\
\hline Smoking & $51 \%$ & $21 \%$ \\
\hline Hypertension & $62.5 \%$ & $30 \%$ \\
\hline Dyslipidaemia & $77 \%$ & $20 \%$ \\
\hline Obesity & $22 \%$ & $10 \%$ \\
\hline DM & $33 \%$ & $30 \%$ \\
\hline $\begin{array}{l}\text { Family history of } \\
\text { CHD }\end{array}$ & $25 \%$ & $23 \%$ \\
\hline Sedentary life style & $21 \%$ & $15 \%$ \\
\hline
\end{tabular}

Note: Patients with multiple risk factors

In table-2 shows distribution of patients according to clinical findings where in case group mean \pm
SD of systolic blood pressure was found $134.75 \pm$ 19.25 and random blood sugar was found in $223.81 \pm 72.18 \mathrm{mg} / \mathrm{dl}$. The following table is given below in details.

Table-2: Distribution of patients according to clinical findings

\begin{tabular}{|l|c|c|}
\hline \multirow{2}{*}{ Clinical Examination } & $\mathbf{n = 8 2}$ & $\mathbf{n}=\mathbf{8 1}$ \\
\cline { 2 - 3 } & Mean $\pm \mathbf{S D} / \mathbf{n}(\mathbf{\%})$ & $\begin{array}{c}\text { Mean } \mathbf{\mathbf { S D }} / \mathbf{n} \\
\mathbf{( \% )}\end{array}$ \\
\hline Heart Rate (per minute) & $87 \pm 15$ & $89 \pm 17$ \\
\hline Respiratory rate $(\mathrm{bpm})$ & $21 \pm 7$ & $19 \pm 5$ \\
\hline Systolic BP $(\mathrm{mmHg})$ & $134.75 \pm 19.25$ & $191 \pm 19.25$ \\
\hline Diastolic BP $(\mathrm{mmHg})$ & $87 \pm 11.52$ & $80 \pm 11.52$ \\
\hline BMI $\left(\mathrm{Kg} / \mathrm{m}^{2}\right)$ & $23.76 \pm 2.51$ & $22.86 \pm 2.51$ \\
\hline
\end{tabular}

In table-3 shows full model of dyslipidemia with CHD. Where is interaction between dyslipidemia and hypertension were found as confounder.

Table-3: Full model of dyslipidemia with CHD

\begin{tabular}{|l|c|c|c|}
\hline Risk factor & $\begin{array}{c}\text { Avg. Number of } \\
\text { Patients (N) \% }\end{array}$ & P value & OR \\
\hline Dyslipidemia & 36 & 0.050 & 2.7 \\
\hline Hypertension & 46.25 & 0.195 & 0.5 \\
\hline Having family history of CHD & 24 & 0.295 & 1.7 \\
\hline Smoker & 36 & 0.926 & 1.0 \\
\hline Diabetes & 31.5 & 0.824 & 1.1 \\
\hline Obese & 16 & 0.512 & 0.8 \\
\hline Dyslipidaemia + hypertension & 47.37 & 0.038 & 6.5 \\
\hline
\end{tabular}

Table-5: One-Sample Statistics

\begin{tabular}{|l|c|c|c|c|}
\hline Variables & $\mathrm{N}$ & Mean & Std. Deviation & Std. Error Mean \\
\hline $\begin{array}{l}\text { CHD with dyslipidemia in } \\
\text { Hypertension group }\end{array}$ & 77 & 1.3117 & .46622 & .05313 \\
\hline
\end{tabular}

Table-6: Relationship of dyslipidemia with coronary heart disease in hypertension

\begin{tabular}{|l|c|c|c|c|c|c|}
\hline \multirow{2}{*}{} & \multicolumn{3}{|c|}{ Test Value =0 } \\
\cline { 2 - 7 } & & $\mathrm{T}$ & $\mathrm{df}$ & $\begin{array}{c}\text { Sig. } \\
\text { Variables }\end{array}$ & $\begin{array}{c}\text { Mean } \\
\text { Difference }\end{array}$ & \multicolumn{2}{|c|}{$\begin{array}{c}\text { 25\% Confidence Interval of the } \\
\text { Difference }\end{array}$} \\
\cline { 5 - 7 } \\
$\begin{array}{l}\text { CHD with dyslipidemia in } \\
\text { Hypertension group }\end{array}$ & 24.688 & 76 & .000 & 1.31169 & 1.2059 & 1.4175 \\
\hline
\end{tabular}

\section{Discussion}

The Ariyanti R and Besral B analysis found that the CHD group was at 50 percent of people reacting with dyslipidemia, while the non-CHD group was at 17.3 percent. Depending on hypertensive condition, theassociation between dyslipidemia and CHD varied. Once controlled forage, in hypertensive respondents or having a history of hypertension, respondents with dyslipidemia are 18 times higher to develop CHD than nondyslipidemic respondents. Although respondents with dyslipidemia are 2,5 times 
higher to experience HCDs than nondyslipidemics for respondents who are not hypertensive or have a history of hypertension. About the evaluation of risk factors of CAD, dyslipidemia was present in $77 \%$ hypertension was found in $62.5 \%$, smoker was $53 \%$, DM was found in $33 \%$. The results of current study with reference to risk factors were similar to previous published papers. ${ }^{8}$ In one article reported that, $75.6 \%$ did not have family history of CHD, did not have smoking habit (53.7\%), did not have hypertension or hypertension history (62.2\%), having diabetes or history of diabetes $(53.7 \%$, and nonobese (62.2\%).

Other study said, the mean of SBP in CHD group was higher than non-CHD group, which was 126.2 mmhg with standard deviation of 21.0, where the lowest SBP was $100 \mathrm{mmhg}$ and the highest was $200 \mathrm{mmgh}$. The average of DBP in CHD group was higher than non-CHD group, which was $85.6 \mathrm{mmhg}$ with standard deviation of 15.5, where the lowest DBP was $60 \mathrm{mmhg}$ and the highest was $120 \mathrm{mmhg} .{ }^{10}$ Where as in our study in case group mean \pm SD of systolic blood pressure was found $134.75 \pm 19.25$ and random blood sugar was found in $223.81 \pm 72.18 \mathrm{mg} / \mathrm{dl}$.

The risk of CHD in patients with dyslipidemia will increase if dyslipidemia is accompanied by one or more other CHD risk factors.

Various studies showed that other factors that can cause cardiovascular disease as hypertension. In our study we found that, the relationship of dyslipidemia with CHD according to hypertension, those with dyslipidemia were more likely to develop CHD compared to those nondyslipidemic. The weakness design of the study is susceptible to selection bias.

\section{Conclusion}

From our study, it is concluded that dyslipidemia and hypertension are established risk factors of prime importance in CHD development. Relationship of dyslipidemia with coronary heart disease in hypertension is significant. Additional research, in particular longitudinal studies, is needed to explore the complex interaction of these factors and to inform policies and programs for the inhibition and supervision of CHDs in Bangladesh.

\section{References}

1. Pahor M, Shorr RI, Somes GW. Diureticbased treatment and cardiovascular events in patients with mild renal dysfunction enrolled in the systolic hypertension in the elderly program. Arch Intern Med 1998;158:1340-5.

2. Kim MC, Kini AS, FusterV.Definitions of acute coronary syndromes:Non-ST elevation myocardial infarction.In: Fuster V, O'Rourke RA, Walsh RA, Poole-Wilson P.Eds. Hurst's the Heart. $12^{\text {th }}$ ed. New York, USA: McGraw Hill; 2008.1314.

3. Berger CJ, Murabito JM, Evam JC. Prognosis after first myocardial infarction: comparison of Q-wave and Non Q-wave myocardial infarction in the framinghamheart study. JAMA 1992; 268: 1545-46.

4. Cooper H, Panza JA. Q wave to guide treatment of myocardial infarction.Lancet 2006 24(367):2035-2037.

5. Genest J, Frohlich J, Fodor G, McPherson R. Recommendations for the management of dyslipidemia and the prevention of cardiovascular disease: summary of the 2003 update, CMAJ. 2003 October 28: 169(9): 921-924.

6. Antman EM, Braunwald E.ST-elevation myocardial infarction. In: Libby P,Bonow RO, Mann DL, Zipes DP. Eds. Braunwald's heart disease. $8^{\text {th }}$ ed. Philadelphia, USA: Saunders; 2008. 12211222.

7. Ariyanti R and Besral B, Dyslipidemia Associated with Hypertension Increases the Risks for Coronary Heart Disease: A Case-Control Study in Harapan Kita Hospital, National Cardiovascular Center, Jakarta, Journal of Lipids Volume 2019, 


\section{Article}

ID

2517013 ,

pageshttps://doi.or/101155/2019/2517013.

8. Bashore TM, Granger CB, Hranitzky P, Patel MR. Coronary heart disease. In: McPhee S, Papakadias MA. Eds. Current medical diagnosis and treatment. $49^{\text {th }} \mathrm{ed}$. New York, USA: McGraw Hill; 2010; 317.

9. R. H. Nelson, "Hyperlipidemia as a risk factor for cardiovascular disease," Primary Care: Clinics in Office Practive, vol, 40, no. 10,pp. 195-211, 201. View at: Publisher site Google Scholar.

10. C.-F. Lin, Y.-H. Chang, S.C. Chien, Y.-H. Lin, and H.-Y. Yeh. "Epidemiology of dyslipidemia in the asia pacific region," International Journal of Gerontology, vol. 12, no. 1, pp. 2-6, 2018. View at: Publisher site Google Scholar.

11. Perkumpulan Endokrinologi Indonesia (PERKENI), Konsensus Pengelolaan Dislipidemia di Indonesia, Pusat Penerbitan Ilmu Penyakit Dalam Fakultas Kedokteran UI, 2015. 